Original Research Paper

\title{
Social Sciences and Social Justice in the Design, Implementation and Evaluation of Measures Against COVID-19-the Case Study of France in 2020
}

\author{
${ }^{1}$ Maria Verykiou, ${ }^{2}$ Laurent Denis and ${ }^{3}$ Cyril Pervilhac \\ ${ }^{1}$ Centre for Research on Health and Social Care Management, SDA Bocconi School of Management, Italy \\ ${ }^{2}$ Monitoring and Evaluation, NGO, United States \\ ${ }^{3}$ Independent, WHO Retiree, France
}

\author{
Article history \\ Received: 06-10-2021 \\ Revised: 01-12-2021 \\ Accepted: 22-12-2021 \\ Corresponding Author: \\ Cyril Pervilhac \\ Independent, WHO Retiree, \\ France \\ Email: pervilhacc@gmail.com
}

\begin{abstract}
The social impact of the COVID-19 pandemic has been profound. This study uses France as a case study to analyze the role of social sciences in the COVID-19 response from March 2020 to February 2021. France's national evaluation reports as well as other secondary sources were used to examine five social science aspects: (i) Basic public health measures in response to COVID-19, (ii) mental health, and cross-sectoral issues in social justice, such as (iii) communication, (iv) civil society and community involvement in decision-making and (v) inequities. Findings indicate poor consideration of inequities in the conception of basic measures such as wearing facemasks, hand hygiene, and social distancing, especially for vulnerable populations, while social components such as mental health, communication, and community engagement are lacking in the evaluation of France's COVID-19 response. Pandemic responses and evaluations of interventions must integrate social science aspects. To this effect, practical recommendations with policy implications are provided to pave the way toward social justice.
\end{abstract}

Keywords: COVID-19, Social Sciences, Evaluation, Policy, Inequities, France

\section{Introduction}

\section{Background}

As observed across the world over the past year, the COVID-19 pandemic highlighted the inadequacy of health system preparedness. It has been termed a "total social event" (Pittet et al., 2021) and the social sciences' support in the response to the pandemic outbreak during the first year in France is documented (Gaille et al., 2020). However, despite COVID-19's major historical and social component and representatives of sociology and anthropology signaling early on the health, economic, but also psychosocial risks of the pandemic (Deroche, 2020) (Brooks et al., 2020), the social sciences remained in a "secondary position in the public arena" (Ferreira et al., 2020) both in terms of the response to an evaluation of the health crisis.

In terms of the response, experiences with pandemic control (i.e., HIV/AIDS, SARS, Ebola), particularly in Africa but also in the global north, including France for the case of HIV/AIDS, have demonstrated the instrumental role of social sciences in the adaptation, implementation, and acceptance of containment measures. Epidemics are "social as well as biological phenomena" (Shah et al., 2020) (Silk and Fefferman, 2021) as illustrated by anthropologists in Africa's Ebola epidemic who recommended the replacement of traditional burial practices that favored the spread of the disease, with safer ones (Nielsen et al., 2015). In the case of COVID-19, the implementation of NonPharmaceutical Intervention (NPI) strategies, which targeted a person or community to prevent the transmission of the pathogen, did not account for different forms of inequalities (Berkhout, 2021) or cultural variations. Despite the signaled importance of collecting and reporting data on socioeconomic determinants as well as race and ethnicity to identify high-risk populations for the development of equitable public health measures (Khalatbari-Soltani et al., 2020), in France, as in other countries, NPIs were driven by limited indicators such as hospitalization and mortality rates, putting forward a biomedical model in the pandemic response (Pittet et al., 2020; Pittet et al., 2021; Deroche, 2020) and initially included lockdowns, curfews, and social distancing restrictions. While the rapid mobilization and response of the 
French health system actors, from administration to citizens, and the resilience of the social protection system is acknowledged (Pittet et al., 2021), such measures impacted social aspects like mental health (Phiri, 2021), household relationships, adverse alcohol use (Niedzwiedz et al., 2020), caregiving for dependents, as well as organizational and educational aspects. As a result, COVID-19 altered the living conditions of populations, introduced strain and instability (Van Bavel et al., 2020), and exacerbated social inequalities by shrinking the social safety net, monopolizing public resources, and leaving many unemployed (Ferreira et al., 2020). The risks following this initial response of confinement and restrictive measures included economic and social upheaval as well as "lost generations". In an Oxfam survey of 295 economists from 79 countries, most respondents felt that gender and racial inequalities are likely to increase as a result of the pandemic and that their governments do not have plans in place to combat them (Berkhout, 2021).

Our goal in this case study is to demonstrate how the pandemic presents an opportunity to rethink social sciences' role and contribution to decision-making and health system preparedness. The objectives are to (i) analyze the results of the essential COVID-19 assessments conducted between March 2020 to February 2021 in France with an emphasis on social sciences, (ii) discuss the reasons why the latter are of importance, and, (iii) suggest ways to better exploit existing evidence with practical policy recommendations in the context of the existing and future pandemics. Emphasis is placed on the pandemic's effect on vulnerable populations and on addressing inequities.

\section{Methods}

\section{Sources}

This case study is based on five key-secondary sources of information on the evaluation of France's COVID-19 response which took place during the period between March 2020 and February 2021. These sources, outlined below, were selected based on their relevance and indepth analysis of the topic.

The national evaluation of the COVID-19 crisis management and anticipated pandemic risks was commissioned by the President of the French Republic, E. Macron, on the $25^{\text {th }}$ of June 2020 to D. Pittet, Chief Medical Doctor in charge of the prevention and infection control service (HUG Geneva). A mid-term report of this evaluation, released on $13^{\text {th }}$ October 2020 , was used for this study, hereafter referred to as the Mid-term report (Pittet et al., 2020) as well as the 179-pages final report with 40 recommendations, completed in March 2021 and released in May 2021, hereafter referred to as the Final report (Pittet et al., 2021). This evaluation focused on the first and second semesters of 2020 until February 2021 , with an impact analysis of mortality and an in- depth macro socio-economic analysis for France, including comparative analyses in Europe.

Further, the 1072-page report to the Senate on the national evaluation of public policies related to big pandemics in light of the COVID-19 health crisis and its management, published in December 2020, was examined, hereafter referred to as the Senate report (Deroche, 2020). This is based on interviews with more than thirty high-level key informants and six roundtables with minutes of key meetings.

In addition, a review of the current status and perspectives on social inequalities in France concerning COVID-19 by the Direction de Recherche des Etudes de l'Evaluation Et des Statistiques (DREES) (Dubost et al., 2020), published in July 2020, was used, presenting a review of the international and French literature, complementing it with statistical analysis of the data for France.

The preliminary results, published in October 2020, from the national survey "Epidemiology and Living Conditions" (EpiCoV) (Warszawski et al., 2020) by DREES were also considered.

Finally, an in-depth analysis of inequities during the pandemic by the Institut de Recherche en Santé Publique (IReSP) (Bajos et al., 2020), released in October 2020, was used. The team comprised of epidemiologists, sociologists, demographers, and economists, whose objective was to estimate the dynamics of the epidemic at the national and departmental levels to measure the effect of living conditions on exposure to the virus and vice-versa. The survey aimed to follow the evolution of the epidemic by interviewing the same populations over several waves.

Additional secondary sources were explored based on a scoping review, to complement the above sources which addressed the same principle themes on the French COVID-19 response in terms of public health measures, mental health, communication, civil society engagement, and inequities from a social sciences perspective. These include newspaper articles, case studies, scientific publications, and a particular meta-analysis that provided a review of the scientific literature on the subject. Recently released Non-Governmental Organizations (NGOs) reports for 2020, such as from Fondation l'Abbé Pierre (FAP) and Secours Populaire, were also reviewed, referring to inequalities. Finally, personal experience in the management of epidemics and pandemics in Africa was drawn upon to put into perspective this case study of France and to provide relevant practical conclusions for future reference.

\section{Analysis}

A Qualitative Secondary Analysis (QSA) methodology was followed (Tate and Happ, 2018), in which the role of social sciences (sociology, anthropology, psychology) in the pandemic response was documented in terms of policy design and their evaluation. An evaluation of the economic aspects was out of the scope of our study and was thus excluded from the 
analysis since it was extensively accounted for in the key sources, in particular the Final report (Pittet et al., 2021).

The analysis focused on five aspects in total, comprising two preventive NPIs addressing: (i) Basic public health measures against COVID-19 (excluding testing) and (ii) mental health, as well as three crosssectoral issues: (iii) Communication, (iv) civil society and community involvement and (v) inequities. This selection is based on 2020 WHO guidelines that informed the pillars of public health measures against COVID-19 (WHO et al., 2021). For each, operational recommendations are provided in the Discussion section to address the gaps observed in the evaluation process and to inform present and future political agendas.

\section{Results}

\section{Basic Measures}

A trend analysis of the basic hygiene measures observed in France between March 2020-July and 2021 is provided by the research agency Santé Publique France (2021) (Fig. 1). For the key measures analyzed in this paper, during the period of March-November 2020 corresponding to that examined in the Final Report: (i) Social distancing by avoiding group and in-person gatherings (green) was adopted strictly as France entered the peak of the first wave on $30^{\text {th }}$ Mar.- $1^{\text {st }}$ Apr. 2020 at $84.7 \%$; however, during the proceeding summer and early fall periods, this percentage ranged between 50-60\%, while even at the second confinement in November 2020 , physical distancing is still maintained at a lower rate of $63 \%$. Further, the practice of (ii) hand hygiene (pink) decreased between $76 \%$ at the first confinement and $70 \%$ at the second confinement, indicating approximately a quarter of the French population did not observe this measure. Finally, the controversy on (iii) wearing a mask (blue) is depicted by an antithetic trend starting from a rate of $15.1 \%$ at the onset of the pandemic and reaching $80 \%$ by the time of the second confinement, with the majority of the population adopting the measure during the summer (70\% on 24-26 $6^{\text {th }}$ Aug. 2020). Although excluded from the time analyzed, it is worth mentioning that because of the ramp-up of the vaccination campaign after the third lockdown, the new variants, and the relaxation of restriction measures, the trends for basic hygiene practices such as the ones described above show a systematic decrease.

While the data point to accomplishments and gaps in the adoption of these measures, it may be subject to high variation between the general and vulnerable populations. In terms of their evaluation, critics from the political bench argue for the relative effect of these measures on impact and transmission rates, as these must evolve concerning the evolution of the virus and its variants' behavior (Deroche, 2020). Further, the Mid-term report, even if the trends were not yet complete, did not analyze how much the populations used these basic measures (i.e., wearing masks, social distancing, hand hygiene) and the Final report did not provide any recommendations on how to improve access and compliance to these basic measures at present because of new waves or future pandemics and used a narrow trend period.

\section{Social Distancing}

The spectrum of the relative enforcement of social distancing in France, from the absolute closure of all restaurant services to the closure of bars at $10 \mathrm{pm}$ and the permission to remove masks in cafés and restaurants during the day, has dichotomized the political scene.

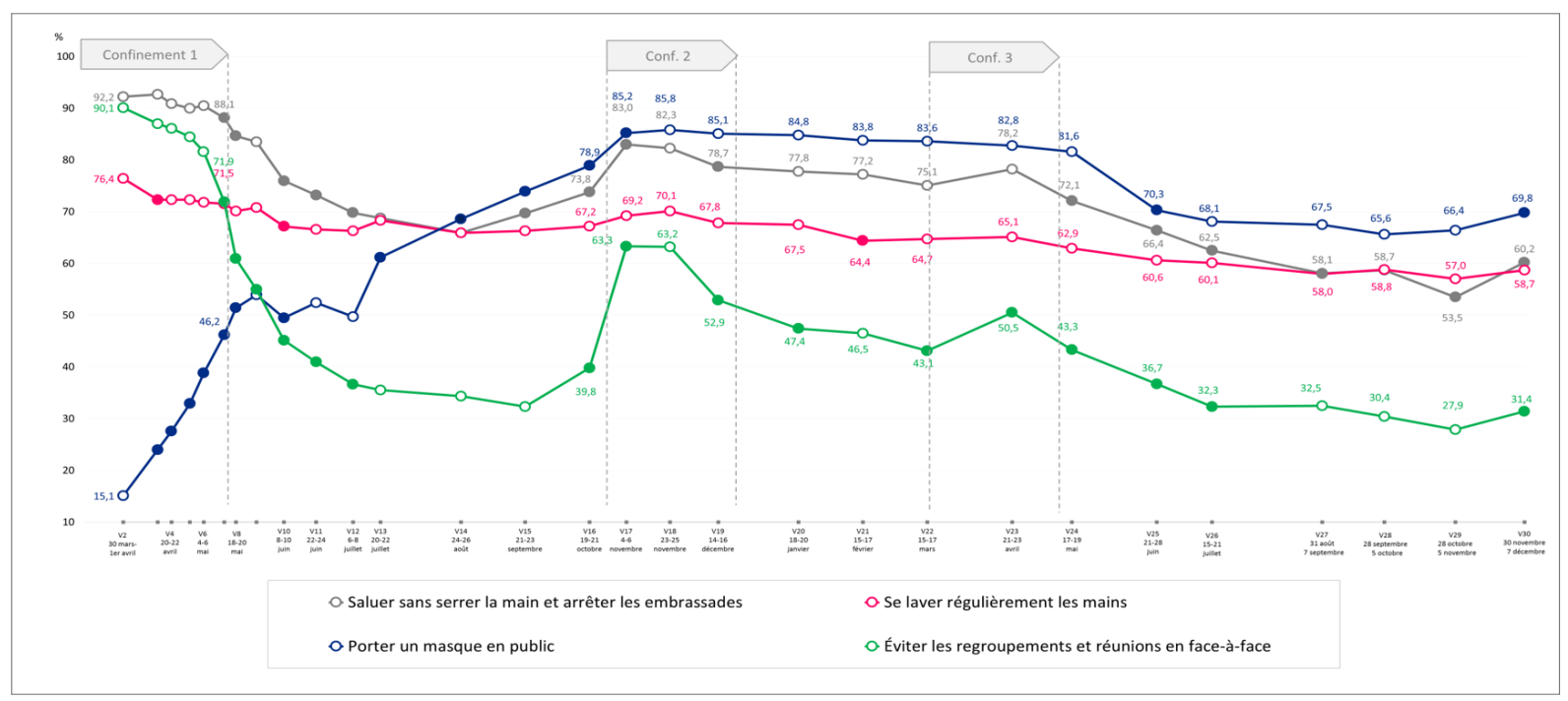

Fig. 1: Trend of the declared systematic adoption of prevention measures (weighted \%) between 30th March 2020-21st July 2021 (Santé Publique France, 2021). Legend: Social greetings without using handshaking or kissing (grey), mask-wearing in public (blue), regular hand-washing (pink), avoiding group gatherings and face-to-face meetings (green) 
Some claimed that these measures have put at a disadvantage certain businesses more than others and questioned the lack of intermediate and equitable solutions (Deroche, 2020). Social distancing was identified as a challenging measure to implement, especially during the spring and summer seasons, which might have contributed to the measure's severity and extent, affecting mostly caregivers and employees in tourism, construction, and commerce (Pittet et al., 2020). Furthermore, the terminology that was used may have affected the extent to which the measure was adopted, as "social distancing" implies the "cut-off of meaningful interactions". Anthropologists argue that the term "physical distancing" may be better suited to reflect the necessity of avoiding physical rather than social contact to prevent the spread of the virus (Deroche, 2020).

\section{Hand Hygiene}

The national evaluation concluded that hand hygiene and social distancing in addition to mask-wearing were essential. These represent moderate measures that must form the core of public communication strategies in the prevention of future surges. However, the trend for hand-washing remains constant over time (Fig. 1), which can be explained by the population coming into and getting out of supermarkets, who are encouraged to disinfect, but not have spontaneously acquired the hand hygiene practice (Pittet et al., 2021). Further, an overall $6 \%$ decrease in the practice was reported between the first and the second lockdown over nine months, despite extensive public health messaging delivered in that period. This suggests a gap in the effective application or design of the measure. The Minister of Health highlighted that the debate on the effectiveness of mask-wearing may have affected public attention towards observing the practice correctly (Deroche, 2020). However, questions around why the practice is not performed or done so poorly and by whom, remain.

\section{Use of Masks}

The Mid-term and Final reports highlight that extensive debates and contradictory opinions on maskwearing have been important challenges, while they identify as accomplishments the scientific, industrial, and public solidarity in the provision of masks and their effective adoption through internet tutorials. At the time of the national evaluation, their effectiveness in public spaces had not yet been demonstrated and there were fears that these provided a false sense of security that may jeopardize the application of other measures (Pittet et al., 2021). Furthermore, the focus on masks was concentrated on logistics (i.e., orders and manufacturing, management of stocks and shortages, types of masks and users, distribution, and messages), rather than on quantifying access, identifying target mask users, measuring demand, determining utilization rates and addressing potential cultural barriers for wide uptake. Despite the early activation of all the mechanisms to combat influenza during COVID-19, several other approaches could have been used to achieve wider adoption of mask-wearing, such as better use of networks and associations (Deroche, 2020) or promotion activities for wearing masks as conducted in 26 neighborhoods in Guyana. Further, research into the reasons for the use or non-use of a mask could be pursued, as was done with condoms for HIV/AIDS, leveraging behavioral surveillance to monitor and link the behaviors with prevalence and incidence among young people as well as other populations (Rehle et al., 2004).

\section{Mental Health}

Early in the pandemic, China called for the inclusion of mental health services in the package of prevention measures (Zhou et al., 2020), and the international community called for collaborations in order "to provide high-quality, timely crisis psychological services to community-dwelling older adults" (Yang et al., 2020). Evidence soon demonstrated the psychological burden of COVID-19 on individuals and the need to align behaviors with containment measures through science communication, moral decision-making, and leadership, among others (Van Bavel et al., 2020). In France, the CoviPrev survey initiated in March 2020 revealed that one-fourth of the population reported being affected by depression, anxiety, dissatisfaction with life, and sleep disturbances, with the highest levels being observed at the beginning of each confinement but falling by up to 5 and $10 \%$ points for depression and anxiety, respectively, during the summer period in-between (Verbeke, 2021; Santé Publique France, 2021).

In the national evaluations, the pandemic's impact on mental health is recognized in several settings, including workplaces and schools (Pittet et al., 2021), as well as in terms of the effects of postponing treatment for various pathologies, such as cancer and mental conditions (Pittet et al., 2020). Further, the lack of understanding of the full psychological impact of COVID-19 on the entire population, beyond institutional psychiatric care, is acknowledged (Deroche, 2020), as well as the challenges in measuring this and making predictions of its consequences, citing the high likelihood of increased depression and anxiety rates in the case of subsequent confinements (Santé Publique France, 2021). A survey on the effect of the confinement under the COCONEL project revealed that the measure was widely supported but at the cost of increased social inequalities and mental health disorders (Deroche, 2020).

A study carried out in April 2020 identified that those in isolation and women are at an increased risk of anxiety, sleep disturbances, concentration problems, and feelings of 
sadness (Dubost et al., 2020). The student community particularly stood out, with a doubling of depression rates from $13.5 \%$ before (23-25 March 2020) to $26.7 \%$ after (30 March-1 April 2020) the onset of the pandemic. While heightened anxiety was reported among the student population following the first confinement, the second confinement was characterized by a worsening of depression cases in terms of severity of symptoms, including suicidal tendencies. Franck (2020) highlights that poor mental wellbeing was also prevalent among individuals with disabilities, farmers, and students. In response to these observations, several behavioral and mental health studies have been launched, including one mandated by the President on January $29^{\text {th }}, 2021$, to investigate the impact of confinements on the psychological status of citizens.

\section{Communication}

France's early response was characterized by weak communication, in contrast to Germany's success in disseminating measures, such as social distancing and availability of diagnostic tests, aided mainly by cultural and organizational factors (Deroche, 2020). Additionally, misinformation and poor access to credible sources of information combined with low literacy rates among the lower-income strata deepened the social divide and contributed to resistance to the timely adoption of measures and the dissemination of preventive practices. The Conseil National de Santé (CNS) was instrumental in communicating the containment measures to manage the crisis. However, it added to the complexity of gathering and unifying experts and to the multiple communication channels, which were at times perceived as disharmonious (Deroche, 2020). The emergence of a plethora of experts on COVID-19, some self-proclaimed and expressing contradictory opinions, and the important number of related articles flooding social media and news channels naturally drew the public towards engaging in the ongoing scientific and political debates. Consequently, the evolution of public interventions and guidelines was not perceived as an adjustment of measures to the new scientific knowledge or other resources that were becoming contemporaneously more available. These were instead perceived as a breach of the guidelines at the time, increasing the level of agitation amongst the public and mistrust towards health authorities. To combat this, the Senate report confirms the necessity of contextualization, clarity, and honesty in the communication of the scientific limitations that confine the translation of evidence into reactive and evolving policies.

Science communication strategies have been criticized for their lack of educational elements, lack of focus on the responsibility of citizens, and not targeting young people (Deroche, 2020). The rise of conspiracy theories and fake news around COVID-19 obscured the reliability of information even when it originated from credible sources and raised the question of who would benefit from the spread of fake news (Green and Cladi, 2020). Communication efforts at the onset of the vaccination campaign in the first trimester of 2021 did little to decrease vaccine hesitancy, which was fueled by a lack of understanding of the factors driving vaccination and a lack of public reassurance by the government (Shah, 2020) (Soullier, 2020). It is at this cultural and behavioral intersection that social scientists can contribute by bringing lessons learned from previous vaccination campaigns, for example against measles in France or the global south, to tailor effective communication practices for the "hard-to-reach" and to overcome vaccine hesitancy and misinformation (Deroche, 2020).

\section{Civil Society and Community Involvement}

In France, social workers were not given due consideration in the initial phase of the response, despite their commendable efforts since the beginning of the pandemic in supporting preventive measures and treatment interventions, but were only considered in a secondary phase, after the closing of community centers. For example, the Senate report criticized the delivery of meals to COVID-19-positive patients in quarantine, where meals were left outside front doors without offering more direct care, as often the fire brigade was called to open doors where numerous meals had accumulated outside. In such instances, service personnel (i.e., social workers) is identified as key prevention personnel to signal the presence of vulnerable populations to the relevant territorial civil protection authorities.

The lack of involvement of civil society and the missed opportunity to incorporate lessons learned from the fight against HIV/AIDS into the COVID-19 response are noted. However civil society engagement mechanisms are not identified in the evaluations, despite the example of the Yellow Vests movement ("gilets jaunes") in the Autumn of 2018, which the President addressed by involving associations that could negotiate local solutions with the movement (Deroche, 2020). Calling for strengthened health democracy by including social scientists and health system users in the CNS (Pittet et al., 2021), the CNS had advocated for a Citizen and Civil Society Committee ("Comité Citoyen et de la Société Civile") in decision-making but was not supported, showing that politicians excluded the civil society from politics. Instead, a COVID-19 control-and-liaison committee was established, which however focused on the role of health information systems and digital technologies in the response instead of liaising with civil society (Deroche, 2020).

\section{Inequities}

While the differential impact of COVID-19 on certain populations is presented above in basic measures and 
mental health, evidence is also presented below on its effect in exacerbating inequities, in geographic, social, and economic terms.

Territorial analysis in the suburbs of Lyon and Ile de France showed populations in peripheral or poorer neighborhoods presented more risk factors for COVID-19 (Dubost et al., 2020). Further, higher exposure risk is found in multi-person households, in non-European immigrant populations, and in persons aged between 30-49 years irrespective of living conditions, with almost double the COVID-19 seroprevalence in priority city areas (Quartier Prioritaire de Politique de la Ville-QPV), which represent poverty-concentrated territories (Warszawski et al., 2020). In Marseille, the homeless population living in the same urban area as the general population demonstrated a significantly increased risk of infection (Loubiere et al., 2021). Economic studies which contain the mapping of populations living under precarious conditions in Paris demonstrate the higher risk and vulnerability of households in precarious territorial units that are typically characterized by being overcrowded, and large, with many youths facing economic uncertainty and low education levels (Goutte et al., 2020). The rate of infection was double in crowded households (defined as $<18 \mathrm{~m}^{2}$ per person) compared to other households, at $9.2 \mathrm{vs}$. $4.5 \%$ respectively. In densely inhabited neighborhoods and households, the lack of an attending doctor was also observed (Deroche, 2020). Interestingly, those who were required to remain active during the confinement periods, such as essential workers, were often residing in priority neighborhoods or close-by, where the disease prevalence was higher (Fondation Abbé Pierre, 2021).

Similarly, aggravating factors of social inequities related to confinement such as comorbidities, mental health, material, and physical safety, social support, housing and isolation, and access to digital technology and education, may have caused a "double" or "triple hardship" within certain sub-populations (Dubost et al., 2020). For instance, it has been shown that women, in addition to constituting the bulk of the health and social care workforce, experienced an increased load of domestic and parental tasks, suffered increased unemployment, as well as high rates of domestic violence. While COVID-19's impact on mortality in men has been show-cased, its impact on increasing social inequities in women as a risk factor is less visible. COVID-19's greater impact on the poor and the elderly is evidenced by correlating mortality rates to a social and age gradient (Yanez et al., 2020).

Finally, locations such as food distribution centers, hostels, and emergency centers, showed a higher prevalence of COVID-19 infections, with one in two people interviewed having contracted the virus in comparison to the one-in-ten incidence found in the general population. In France, 5.5 million individuals in need of food support benefitted from $€ 1.5$ billion of food aid per year, but since April 2020, there has been an increase of
25-30\% in demand (Ouest France, 2020). Requests for food aid from the Secours Populaire shot up by $45 \%$, while from the "Restos du Coeur" reached $45 \%$ in Seine-Saint-Denis and $30 \%$ in Paris. With a big part of their volunteers aged 70 years and over, the FAP, Red-Cross, and Secours Populaire noted fewer human resources to sort, stock, and distribute the goods, due to the confinement restrictions (Birchem, 2020). As per the Ministry of Solidarity and Health, the budget for food aid is projected to increase substantially for the 2021-2027 period, with the figure of people in need of food aid reaching 8 million at the end of 2020 compared to 5.5 million at 2019 (Rey-Lefebvre, 2020). In addition, institutions of care for the elderly (EHPAD) or the handicapped, social residences for children or migrants, and prisons are identified as locations where the risk of infection was highest, with similar mortality rates than in other countries' respective institutions (Pittet et al., 2021). However, no conclusions are inferred regarding the level of care provided for COVID-19 patients in these institutions. This topic will be addressed through a newly created and dedicated platform for health research focusing on populations living in care institutions (Deroche, 2020). Further, specialized COVID-19 accommodation centers were opened for those mildly ill, without a home, or who could not stay at their home due to limited opportunity for isolation and increased risk of comorbidities. The percentage of COVID-19 positive cases in such accommodation centers in the Ile-de-France during the summer of 2020 was $52 \%$ compared to $10 \%$ in the rest of the population. Social sciences are essential to address and overcome these inequities, as discussed later, and bridge the gap between the Solidarity and Health components of the French Ministry of Solidarity and Health.

\section{Discussion}

\section{Discussion of Results and Practical Policy Recommendations}

Our analysis was limited to the period of March 2020-February 2021 and excluded the impact of the preventive vaccination campaign. This was to ensure consistency with the data analyzed in the Final report, which was only released and made available in May 2021 and which limited the timing and scope of this case study. Further, due to time limitations, the case study excluded the analysis of documents such as detailed national plans and strategies and for the same reason, access to key informants as primary sources of information was not possible. The Senate report largely compensates for the latter, given that it includes the opinions on the pandemic response of more than 30 politicians and other experts. However, the subjective nature of the Senate report constitutes a source of bias, as a repository of politicians' opinions and interpretation of evidence. Finally, the case 
study provides a wealth of information and perspectives on the measures adopted but less so on their effectiveness due to the challenges of measuring their impact.

Despite the time limitations of this case study, the analysis of basic public health measures in the first year of the pandemic presented in this paper is relevant and applicable to the second year, especially as the examined interventions are beneficial to the health and well-being of populations worldwide, even in non-pandemic periods (Muller et al., 2021). NPIs can significantly contain the COVID-19 pandemic, with distancing and the simultaneous implementation of two or more NPIs associated with decreased virus transmission (Bo et al., 2021). Indeed, the complete chain of measures must be observed to effectively combat COVID-19 (Deroche, 2020), as demonstrated during the HIV/AIDS pandemic (Piot and Coll Seck, 2001) (UNAIDS, 2010). Compared to highly intrusive options such as curfews and lockdowns, governmental support to vulnerable populations, for example through food assistance and risk-communication strategies tailored to the local context are strongly recommended, as these measures may also foster higher compliance (Haug et al., 2020). Nonetheless, all prevention measures, backed up by social sciences, need to be results-based with hard indicators and targets that are monitored over the short and medium-term. We reported on these trends in the Results section (Fig. 1) but the qualitative studies explaining the changes among vulnerable groups still need to be undertaken as in Germany (Fisher et al., 2020).

Further, given the social and mental health impact of COVID-19 containment measures recognized by the WHO (De Miguel, 2021), social sciences merit urgent consideration by expert researchers for the prevention and control of diseases at the local and international levels alike (Green and Cladi, 2020). The interdependency of health, social, ecological, economic, financial, and political parameters (Van Bavel et al., 2020) (Ferreira et al., 2020) must be accounted for to design effective interventions, as exemplified by the BESSI collaboration (Michie and West, 2020) (BESSI, 2021). Designing effective NPIs must thus also take into consideration community-based care, the Primary Health Care (PHC) system, which is characterized by a shortage of staff, general practitioners, and nurses, especially in the rural areas and suburbs of big cities, gaps in continuity of care, limited preventive care accessibility to vulnerable populations and lack of resources. However, the evaluations focused on hospital bottlenecks and deaths at the tertiary level (Pittet et al., 2021), thus missing the opportunity to highlight the importance of strengthening health systems as a whole to overcome the social injustice in access to services in the long-term and achieve higher effectiveness of the basic measures against COVID-19, as learned from the recent Ebola response. Because of the gap between community and state provision, a strengthened community-based approach for social and health care surveillance and delivery is called for, through state partnerships with community-based associations.

Due to the extent and nature of the impact of the pandemic, public health responses must take into account the embedded behaviors, social environments, and structures that were conducive to the emergence and transmission of COVID-19 (Michie and West, 2020). Public health is not limited to the health sector but seeks to coordinate collective efforts, based both on scientific knowledge and citizen and civil society engagement, based on a shared political project. Community engagement, exemplified by Scandinavian countries, thus, lies at the core of public health, which can be reinforced following a multidisciplinary approach and improved training of health professionals (Deroche, 2020; Pittet et al., 2021). Targeting public health messages through trusted community leaders, especially in marginalized communities, building partnerships between public health authorities and organizations that are working directly with them, and disseminating information on recognizing inaccurate sources of information through discussions between the policy community and humanities experts, can help to safeguard the public from misinformation (Shah, 2020). Content must be carved around the collective social responsibility that individual behaviors bear in the fight against the virus (Van Bavel et al., 2020).

In conclusion, the evaluations illustrate the dominance of impact markers for health and the economy, resulting in the formulation of "Propositions" largely overlooking the present and, consequently, future social inequities. Because of better exploiting social sciences and considering these gaps, we propose operational recommendations for each of the five aspects of our analysis (basic measures, mental health, communication, community engagement, and inequities) (Supplementary Table S1) for the institutions and agencies involved in the response. We also provide practical applications to complement the "Propositions" formulated in the French evaluations, using four examples (Supplementary Table S2).

\section{Evaluation as a Tool for Social Justice}

According to the literature, vulnerable populations (Van Bavel et al., 2020), (Bajos et al., 2020), (Pittet et al., 2020), (Dubost et al., 2020) include the homeless, those who do not have access to sanitary services or clean water, those living in conditions where physical distancing cannot be observed such as prisons and refugee camps, persons without health insurance and with limited access to health services, or those in occupations that do not allow for remote working such as cleaning, retail, agricultural labor, where employees depend on a daily wage, or who need to use public transport to reach their work. However, due to the lack of a common definition or 
methodology for their identification, prioritization mechanisms for vulnerable populations have not been established by the Haut Conseil de Santé Publique (HCSP) in France, as opposed to the USA and the UK. Indeed, the decree dated 29 ${ }^{\text {th }}$ August 2020 which officially identifies the populations eligible for partial unemployment compensation was criticized by the President of the Scientific Committee as restrictive only to populations vulnerable to COVID-19 (Jacquot, 2020).

In the French evaluation reports, references to targeted interventions for the benefit of vulnerable populations are rare. However, social science research can contribute to the creation of public policies, including adapted health and psychosocial strategies, that ensure that activities are tailored to specific populations, ethnic groups (Gorce, 2021), and geographies. Such activities can be informed by past experiences with HIV/AIDS, or local scale COVID-19 responses, with the example of Nigeria (Irwin et al., 2021), where social sciences were used for targeted measures to tackle inequity instead of imposing general lockdowns. In its concluding remarks, a social science study pointed out that it may be too late to work on medical predispositions and pre-existing health conditions that might put a certain group of persons at higher risk, therefore it is wiser to target upstream and downstream mechanisms, like exposure to COVID-19 and access to treatment, respectively (Dubost et al., 2020). This may partially explain why the evaluation reports did not consider addressing inequities as an issue.

Social sciences as well as aspects relating to overcoming inequities were largely under-represented in France's 2020 public policy evaluation processes, despite the World Health Organization's guidelines for Intra Action Reviews (IAR) placing social sciences at the core of public health approaches (WHO, 2020) (Shah, 2020). Illustrative of this is the composition of the team responsible for the design of the evaluation reports (Oct. 2020, May 2021) as well as the CNS for COVID-19 which was founded in March 2020 and is the main advisory body to the French Government (Blaize, 2021). As social scientists were largely absent from the evaluations conducted by leading public health bodies in France, intervention measures may not have fully reflected COVID-19's social gradient. Indeed, the attention to the latter is lacking in the national evaluations analyzed in this paper, with "sociology", "anthropology" or "psychology" not mentioned per se and limited only to the provision of an analysis of the crisis's social consequences through meeting key informants involved in the social response and a case-study in a local underprivileged territory (Pittet et al., 2021). The prevention measures introduced in France thus hit a wall when confronted with social inequities, as inequalities in terms of professional circumstances, promiscuity, and differential access to protection measures are deeply embedded in the French society (Dubost et al., 2020).

Further, while trends for basic public health measures were already available in August 2020, they were not included in the Mid-term report for the preliminary analysis and recommendations before France faced its second wave.

The above-mentioned gaps point to the conclusion that evaluations must be more comprehensive, participative, and timely, to inform a more effective and equitable response, provided social sciences are included in governance and research activities.

In terms of governance, the lack of involvement by citizen associations in decision-making and solution design is noted as the poor consideration of social determinants, though singularly documented through the exposure gradient and mortality (Dubost et al., 2020). In response to this, the governing body of the CNS recommended its thematic diversification through expansion to other domains, such as economic and social, to be able to conduct comprehensive evaluations of the propositions put forward to the council (Deroche, 2020). However, responsibilities between the various layers of advising bodies were unclear and added to the bureaucracy and complexity of final public sector decision-making. This gap between risk evaluation and management is present also in other institutions, like the HCSP, which seems to be a competing or duplicating entity to numerous other existing specialized agencies (Pittet et al., 2020). As a solution, an inter-ministerial crisis cell («une cellule interministérielle de crise») for decision-making chaired by the prime minister or a minister has been presented, consisting of experts offering their insights but who are not accountable for decisionmaking (Deroche, 2020).

In terms of research, both bio-medical and social domains were challenged by the novelty of the COVID-19 virus, which can partially explain the limitations of the two evaluations and can justify why decisions were not able to be taken based on these. As the continuous evolution of the pandemic constantly defines a new status quo to respond to, certain findings and perspectives are quickly rendered outdated, thus justifying the delays in the formulation and dissemination of the evaluation findings. To combat this, WHO has recommended the use of regular IARs for COVID-19 (WHO, 2020), to which national research bodies like the "Agence Nationale de Recherche Nord and Sud sur le SIDA et les hépatites virales" (ANRS), have considerably modified their procedures to carry out evaluations very quickly (Deroche, 2020). Following such an approach, the findings from the evaluations we reviewed could have been rapidly leveraged in the context of the current COVID-19 response while lessons for future 
pandemics, which eventually became the focus of the evaluation, could have been drawn later. With WHO-Europe not having the authorization to disseminate the IARs from their member states, the blame and shame culture still appear to prevail, rather than learning quickly and collectively with a few countries such as Spain and Sweden now advocating for the internal and independent evaluations of institutions (Garcia-Basteiro et al., 2020) (Swedish Ministry of Health and Social Affairs, 2020).

Some considerations are provided in Table 1 for the conduct of participative and comprehensive evaluations for decision-making towards addressing social inequalities. These are applicable broadly, including to other country contexts or pandemics.

Table 1: Recommendations for addressing social inequalities in the conduct of public health crisis evaluations

\begin{tabular}{ll}
\hline Evaluation aspect & Recommendations \\
\hline Design & $\begin{array}{l}\text { Engagement of social scientists (social epidemiologists, psychologists, anthropologists, etc.,), local and } \\
\text { national experts, civil society, communities, and social institutions } \\
\\
\text { Early identification of vulnerable populations and ethnic groups for inclusion in the design of targeted } \\
\text { measures, outreach methods, and their monitoring and evaluation }\end{array}$ \\
\hline Scope & $\begin{array}{l}\text { Inclusion of behavioral, social, and humanitarian aspects of basic measures and other NPIs, as well as mental } \\
\text { health and basic measures in the scope of health systems' evaluations }\end{array}$ \\
\hline Methods & $\begin{array}{l}\text { Social sciences, as per the Final report, are to be linked to research in health from the onset of projects and } \\
\text { included in pluri-, inter-, and trans-disciplinary approaches }\end{array}$ \\
\hline Timeline & Performance of rapid assessments (3-6 month turnover) as per the WHO IARs \\
\hline Financing & $\begin{array}{l}\text { Earmarking a minimal budget for social sciences-supported activities (based on leveraging minimal } \\
\text { resources for a health system component, such as the monitoring and evaluation of HIV/AIDS) }\end{array}$ \\
\hline Dissemination & $\begin{array}{l}\text { Promotion of a learning platform within Europe (by regions, and international) for lessons-learned exchange } \\
\text { per intervention (i.e., what works or not) } \\
\text { Articulation of social challenges at national and international levels, between policy and civil society actors }\end{array}$ \\
\hline
\end{tabular}

Supplementary Table S1: Practical policy recommendations for the five aspects analyzed in the paper: basic measures, mental health, inequities, communication, and civil society and community involvement

\begin{tabular}{|c|c|}
\hline Aspect & Practical policy recommendations \\
\hline Basic measures & $\begin{array}{l}\text { 1. Tailor studies to improve the understanding of the basic measures according to different populations } \\
\text { and contexts in-country } \\
\text { 2. Further advance the acceptance, access (beyond the stock shortages), and use of the basic measures } \\
\text { (i.e., masks) by various populations } \\
\text { 3. Establish monitoring and rapid analysis of behavioral indicators for infection and NPIs to identify } \\
\text { barriers and groups for targeted strategies } \\
\text { 4. Establish roundtables and task forces with social scientists (i.e., anthropologists, sociologists, } \\
\text { psychologists) for the exchange and sharing of recommendations with the Government or CNS }\end{array}$ \\
\hline Mental health & $\begin{array}{l}\text { 1. Include mental health in national plans, strategies, and budgets from the onset of a crisis } \\
\text { 2. Launch from the onset the monitoring of the impact of confinements on mental health } \\
\text { 3. Evaluate the effectiveness of measures for future decision-making regarding the scale-up or design of } \\
\text { context-dependent targeted strategies (i.e., students) or innovations (i.e., online support) }\end{array}$ \\
\hline Inequities & $\begin{array}{l}\text { 1. Early identification of vulnerable populations and establishment of monitoring strategies taking into } \\
\text { account social and behavioral aspects as well as the long-term effects of the implemented measures to } \\
\text { disseminate these to associations and NGOs to inform policy } \\
\text { 2. Context-specific tailoring of measures according to the living and basic needs arrangements of } \\
\text { vulnerable populations (i.e., elderly homes, schools and universities, prisons, unemployed) or } \\
\text { geographical sites (i.e., hot spots, some suburbs) }\end{array}$ \\
\hline Communication & $\begin{array}{l}\text { 1. Development of targeted communication strategies with the support of behavioral scientists, tailored to the } \\
\text { needs of diverse populations, particularly the most vulnerable, depending on the pandemic dynamics } \\
\text { 2. Delivery of targeted messages to key populations by engaging social scientists through the existing } \\
\text { official bodies } \\
\text { 3. Monitoring of the "infodemic" through information technology and social media to overcome health } \\
\text { misinformation, adapt strategies to the changing needs of the pandemic, and disseminate them through } \\
\text { infodemiology conferences (WHO, 2020) }\end{array}$ \\
\hline $\begin{array}{l}\text { Civil Society and } \\
\text { Community } \\
\text { Involvement }\end{array}$ & $\begin{array}{l}\text { 1. Civil society engagement for strengthening the PHC system and involvement of citizen associations' working } \\
\text { with vulnerable populations to enhance social justice and access to services, including via evaluation } \\
\text { 2. Explore as a solution the set-up of a «Comité Citoyen et de la Société Civile », or other alternatives, } \\
\text { and assess its effectiveness in involving communities and civil society in the design of local responses }\end{array}$ \\
\hline
\end{tabular}


Supplementary Table S2: Practical applications of the final report propositions relating to organizational restructuring and responsibilities

Final report structural propositions $\quad$ Translation into practical applications

Proposition $n^{\circ} 21$ : In case of establishment of an independent ad-hoc council for informing decisionmaking during a health crisis, ensure that it integrates at least:

-Representatives of the various disciplines (health, economy, social sciences)

-Representatives of existing expert bodies and agencies

Proposition $n^{\circ}$ 13: Structuring the research teams of the INSERM and the new ANRS-emerging infectious diseases under one priority program.

Proposition $n^{\circ} 2$ : Develop a continued collaboration between the SGDSN and social sciences research institutions specializing in the organizational analysis of crisis management.

Proposition $n^{\circ} 3$ : Initiate a continuous work process on human resources for crisis management between the SGDSN and each ministry to map the needs and skills, and deliver training to ensure over time the

Amend the composition of the Haut Conseil Scientifique to include at least $1 / 3$ social scientists, and $1 / 3$ economists, to complement the existing biomedical lead, to inform in real-time the government for policy-making in social aspects (rather than retrospectively through a laborious and tardive evaluation, or not at all).

Development, in collaboration with the Secrétariat Général de la Défense et de la Sécurité Nationale (SGDSN), of a costed preparedness plan for the activities of the Conseil, public agencies (INSERM, new ANRS), universities, foundations, CSOs, under one priority program. The funding envelope should be substantial in light of the returns/benefits and high present costs of reanimation and treatments (i.e., hospitals), and vaccinations (i.e., research and campaign).

An in-depth assessment of the roles, challenges, and achievements of the existing structures (i.e., state actors and public sector committees, academia, CSOs) in investigating the contribution of inequities in the health crisis and addressing them, by using the sociology of organization analysis (Mintzberg, 1979), and proposing structural improvements. maintenance of crisis management skills.

\section{Conclusion}

The case study of France demonstrates the differential impact of COVID-19 on socially vulnerable populations and argues that a central role must be played by communities to ensure an inclusive, equitable, and effective response. To prevent further infections, measures such as social distancing, hand hygiene, and mask-wearing must be informed by behavioral psychology research to determine a population's willingness to accept and adopt these measures and anticipate interventions to address potential negligence or resistance and counter risky behaviors such as mask avoidance in public spaces (Green and Cladi, 2020). Indeed, our opinion is that understanding the relationship between evaluation, decisionmaking and communication can transform evidence into effectively implemented public health measures.

To render the response to COVID-19 and future pandemics more equitable, the social sciences (i.e., sociology, anthropology, psychology) must address many questions: Who are the most vulnerable populations where inequities must be addressed? Where are they located? What is the best way to engage and reach vulnerable communities and what should the role of civil society associations, NGOs, and local government representatives be? How do formulate messaging and communications to ensure it resonates among these populations? How will the impact of the measures promoted among them be monitored/evaluated and assessed? Considering the G7 leaders' "USD 4.3 billion to finance equitable access to tests, treatments, and vaccines in 2021 " (G7, 2021a) commitment, it is reasonable to argue that investing in tools specific for addressing the respective social issues is a relatively small cost with a valuable sustainable benefit and impact (G7, 2021b).

The present analysis of France's COVID-19 response could be complemented by further research to improve our understanding of the importance and role of social sciences in pandemic preparedness and response to imminent new waves and future pandemics. Future research efforts should leverage detailed data from secondary sources beyond those used in this analysis, including plans, committee reports, detailed strategies, and measures implemented. In addition, primary data from interviews with community leaders, experts, and decision-makers should also be collected. A comprehensive longitudinal observational research study with economic and social endpoints could provide evidence on the long-term impact of public health measures implemented among vulnerable populations in France but also in other countries. With regards to future pandemics, a sociological analysis of governance bodies and how effectively these are organized to take rapid and evidencebased decisions would be beneficial (Mintzberg, 1979).

In conclusion, the findings presented here provide a first critical review of the importance of including social sciences stakeholders as well as approaches in the development of pandemic response plans from the onset. Social sciences have a role to play in informing decision-making on the design, implementation, and adoption of effective NPIs in the short- and long-term to address the COVID-19 pandemic and beyond, in preparing for the emergence or reemergence of other infectious diseases (Van Bavel et al., 2020). It should also be noted that the current pandemic may evolve into an endemic disease with emerging variants 
calling for dynamic and tailored responses over time. This has been the case with viruses like influenza or HIV/AIDS for example. Pandemic preparedness and response should include epidemiological surveillance and early detection of outbreaks, establishing rapid responses, producing and sharing data, knowledge, and technology, in addition to a profound understanding of a community's needs and its acceptance of basic prevention measures, using social sciences. Only then will social justice be manifested in public policies.

\section{Acknowledgments}

We thank Stephane Cullati for his contribution to the review of the paper throughout its development and Lucia Brugnara. We also thank Anneline Blankenhorn and Helen Banks who contributed to the final editorial process.

\section{Authors' Contributions}

Maria Verykiou: Synthesized, analyzed, and finalized the manuscript. Reviewed and adapted the paper at different stages. Critically reviewed and updated the paper until the final publication.

Laurent Denis: Co-developed the case study, acquired the data, and conducted the preliminary analyses. Substantial inputs to the final manuscript. Critically reviewed the paper until the final publication.

Cyril Pervilhac: Led and co-developed the case study, acquired the data conducted the preliminary analyses. Drafted and wrote the original manuscript and reviewed it throughout. Substantial inputs to the final manuscript. Critically reviewed the paper until the final publication.

\section{Ethics}

The authors declare no competing interests.

Consent for the reproduction of Fig. 1 was granted by the Service Droits Santé Publique France.

\section{References}

Bajos, N., Warszawski, J., Pailhé, A., Jusot, F., Spire, A., \& Lydie, N. (2020). Les inégalités sociales au temps du COVID-19. Questions de santé publique. https://hal.archives-ouvertes.fr/hal-03086996/

Berkhout. (2021). The Inequality Virus. Retrieved from https://www.oxfam.org/en/research/inequality-virus

BESSI. (2021). Behavioral, Environmental, Social, and Systems. BESSI: https://www.bessi-collab.net/

Birchem, N. (2020, July). La précarité alimentaire va s'aggraver dans les mois qui viennent. La Croix l'Hebdo.
Blaize, A. (2021). Conseil Scientifique du COVID: composition, membres, rapport. Retrieved from Le Journal des femmes: Santé: https://sante.journaldesfemmes.fr/fichesmaladies/2641195-conseil-scientifique-coronaviruscovid-constitution-gouv-conflit-interet-membresrole-avis/

Bo, Y., Guo, C., Lin, C., Zeng, Y., Li, H. B., Zhang, Y., ... \& Lao, X. Q. (2021). Effectiveness of non-pharmaceutical interventions on COVID-19 transmission in 190 countries from 23 January to 13 April 2020. International Journal of Infectious Diseases, 102, 247-253. doi.org/10.1016/j.ijid.2020.10.066

De Miguel. (2021). Las variantes del virus no son el inicio de otra pandemia. El Pais. https://elpais.com/sociedad/2021-02-10/lasvariantes-del-virus-no-son-el-inicio-de-otrapandemia.html

Deroche. (2020). Rapport No199, Sénat, Session ordinaire de 2020-2021,8 décembre 2020, Rapport fait au nom de la commission d'enquête (1) pour l'évaluation des politiques publiques face aux grandes pandémies à la lumière de la crise sanitaire de la COVID-19 et de sa gestion. Senat http://www.senat.fr/rap/r20-199-2/r20-199-2.html

Dubost. (2020). Les inégalités sociales face à l'épidémie de Covid-19 État des lieux et perspectives. Direction de Recherche des Etudes de l'Evaluation et des Statistiques (DREES). https://drees.solidaritessante.gouv.fr/publications/les-dossiers-de-ladrees/les-inegalites-sociales-face-lepidemie-decovid-19-etat-des

Ferreira, C. M., Sá, M. J., Martins, J. G., \& Serpa, S. (2020). The COVID-19 contagion-pandemic dyad: A view from social sciences. Societies, 10(4), 77. doi.org/10.3390/soc10040077

Fisher, D., Teo, Y. Y., \& Nabarro, D. (2020). Assessing national performance in response to COVID-19. The Lancet, 396(10252), 653-655. doi.org/10.1016/S0140-6736 (20)31601-9

Fondation Abbé Pierre. (2021). 26e rapport sur l'état du mal-logement en France 2021.

https://www.fondation-abbepierre.fr/documents/pdf/reml2021_rapport_sur_letat _du_mallogement-web.pdf

Franck, N. (2020). COVID-19 et détresse psychologique: 2020, l'odyssée du confinement. Odile Jacob.

G7. (2021a). Joint statement of G7 Leaders | 19 February 2021. G7 UK 2021: https://www.g7uk.org/jointstatement-of-g7-leaders-19-february-2021/

G7. (2021b). 100 Days Mission to respond to future pandemics. G7 UK 2021:

https://assets.publishing.service.gov.uk/government/ uploads/system/uploads/attachment_data/file/99276 2/100_Days_Mission_to_respond_to_future_pande mic_threats_3_.pdf 
Gaille, M., Terral, P., Askenazy, P., Aubry, R., Bergeron, H., Becerra, S., ... \& Zouache, A. (2020). Les sciences humaines et sociales face à la première vague de la pandémie de Covid-19-Enjeux et formes de la recherche (Doctoral dissertation, Centre National de la Recherche Scientifique; Université Toulouse III-Paul Sabatier). https://halshs.archivesouvertes.fr/halshs-03036192/

García-Basteiro, A., Alvarez-Dardet, C., Arenas, A., Bengoa, R., Borrell, C., Del Val, M., ... \& LegidoQuigley, H. (2020). The need for an independent evaluation of the COVID-19 response in Spain. The Lancet, 396(10250), 529-530. doi.org/10.1016/S0140-6736(20)31713-X

Gorce, B. (2021). Statistiques ethniques, l'impossible débat. La Croix: https://www.lacroix.com/France/Statistiques-ethniqueslimpossible-debat-2021-06-29-1201163962

Goutte, S., Péran, T., \& Porcher, T. (2020). The role of economic structural factors in determining pandemic mortality rates: Evidence from the COVID-19 outbreak in France. Research in International Business and Finance, 54, 101281. doi.org/10.1016/j.ribaf.2020.101281

Green, S. \& Cladi, L. (2020). Behavioral, environmental, social, and systems interventions against COVID-19. BMJ (370). doi:10.1136/bmj.m2982.

Haug, N., Geyrhofer, L., Londei, A., Dervic, E., DesvarsLarrive, A., Loreto, V., ... \& Klimek, P. (2020). Ranking the effectiveness of worldwide COVID-19 government interventions. Nature human behavior, 4(12), 1303 1312. doi.org/10.1038/s41562-020-01009-0

Irwin, et al. (2021). Using data to combat the ongoing crisis and the next, in Nigeria.

https://blogs.worldbank.org/opendata/using-datacombat-ongoing-crisis-and-next-nigeria

Jacquot, G. (2020). Populations vulnérables : pour le professeur Delfraissy, le décret du 29 août «tombe très mal». Public Senat:

https://www.publicsenat.fr/article/parlementaire/pop ulations-vulnerables-pour-le-professeur-delfraissyle-decret-du-29-aout

Khalatbari-Soltani, S., Cumming, R. C., Delpierre, C., \& Kelly-Irving, M. (2020). Importance of collecting data on socioeconomic determinants from the early stage of the COVID-19 outbreak onwards. J Epidemiol Community Health, 74(8), 620-623. doi.org/10.1136/jech-2020-214297

Loubiere, S., Monfardini, E., Allaria, C., Mosnier, M., Allibert, A., Ninove, L., ... \& Tinland, A. (2021). Seroprevalence of SARS-CoV-2 antibodies among homeless people living rough, in shelters and squats: A large population-based study in France. PloS one, 16(9), e0255498. doi.org/10.1371/journal.pone.0255498
Michie, S., \& West, R. (2020). Behavioral, environmental, social, and systems interventions against COVID-19. BMJ, 370. doi.org/10.1136/bmj.m2982.

Mintzberg, H. (1979). The Structuring of Organizations. https://www.nrc.gov/docs/ML0907/ML090710600.pdf

Müller, O., Razum, O., \& Jahn, A. (2021). Effects of nonpharmaceutical interventions against COVID-19 on the incidence of other diseases. The Lancet Regional Health-Europe, doi.org/10.1016/j.lanepe.2021.100139.

Niedzwiedz, C. L., Green, M. J., Benzeval, M., Campbell, D., Craig, P., Demou, E., ... \& Katikireddi, S. V. (2021). Mental health and health behaviors before and during the initial phase of the COVID-19 lockdown: longitudinal analyses of the UK Household Longitudinal Study. J Epidemiol Community Health, 75(3), 224-231. doi.org/1136/jech-2020-215060.

Ouest France. (2020). Banques alimentaires. Claude Baland élu président de l'association. Ouest France: https://www.ouestfrance.fr/societe/alimentatio/banques-alimentairesclaude-baland-elu-president-de-l-association6882465

Phiri. (2021). An evaluation of the mental health impact of SARS-CoV-2 on patients, general public and healthcare professionals: A systematic review and meta-analysis. E Clinical Medicine, 34. doi.org/10.1016/j.eclinm.2021.100806.

Piot, P., \& Coll Seck, A. M. (2001). International response to the HIV/AIDS epidemic: Planning for success. Bulletin of the World Health Organization, 79, 1106-1112.

https://www.scielosp.org/article/bwho/2001.v79n12/ 1106-1112/

Pittet et al. (2020). Rapport d'étape: Mission indépendante nationale sur l'évaluation de la gestion de la crise COVID-19 et sur l'anticipation des risques pandémiques. République Française. Elsevier: https://www.elsevier.com/_data/assets/pdf_file/000 8/1085435/6a60183240df51eb80272ba1180610245 $121 \mathrm{fe} 3 \mathrm{~d} . \mathrm{pdf}$

Pittet, D., Boone, L., Moulin, A. M., Briet, R., \& Parneix, P. (2021). Mission indépendante nationale sur l'évaluation de la gestion de la crise COVID-19 et sur l'anticipation des risques pandémiquesRapport final. Réseau de Prévention des Infections Associées aux Soins.

https://www.preventioninfection.fr/actualites/missio n-independante-nationale-sur-levaluation-de-lagestion-de-la-crise-covid-19-et-sur-lanticipationdes-risques-pandemiques-rapport-final/ 
Rehle, T., Lazzari, S., Dallabetta, G., \& Asamoah-Odei, E. (2004). Second-generation HIV surveillance: better data for decision-making. Bulletin of the World Health Organization, 82, 121-127. https://www.scielosp.org/article/bwho/2004.v82n2/1 21-127/

Rey-Lefebvre, I. (2020). L'Europe vient à point nommé financer l'aide alimentaire en France. Le Monde: https://www.lemonde.fr/societe/article/2020/11/02/1europe-vient-a-point-nomme-financer-l-aidealimentaire-en-france_6058245_3224.html.

Santé Publique France. (2021). COVI Prev: Une enquête pour suivre l'évolution des comportements et de la santé mentale pendant l'épidémie de COVID-19. Santé Publique France.

https://www.santepubliquefrance.fr/etudes-etenquetes/coviprev-une-enquete-pour-suivre-1evolution-des-comportements-et-de-la-santementale-pendant-l-epidemie-de-covid-19\#block242830

Shah, H. (2020). Global problems need social science. Nature, 577(7789), 295-296. doi.org/10.1038/d41586-020-00064-x.

Silk, M. J., \& Fefferman, N. H. (2021). The role of social structure and dynamics in the maintenance of endemic disease. Behavioral ecology and sociobiology, 75(8), 1-16. doi.org/10.1007/s00265-021-03055-8.

Soullier, L. (2020). « On ne peut pas balayer les antivaccins et les sceptiques en les réduisant au complotisme ». Le Monde.

https://www.lemonde.fr/politique/article/2020/11/17 /antivaccins-on-ne-peut-pas-balayer-les-sceptiquesen-les-reduisant-aucomplotisme_6059990_823448.html

Swedish Ministry of Health and Social Affairs. (2020). Mats Melin to chair COVID-19 inquiry in Sweden. Government Offices of Sweden: https://www.government.se/pressreleases/2020/06/mats-melin-to-chair-covid-19inquiry-in-sweden

Tate, J. A., \& Happ, M. B. (2018). Qualitative secondary analysis: a case exemplar. Journal of Pediatric Health Care, 32(3), 308-312. doi.org/10.1016/j.pedhc.2017.09.007

UNAIDS. (2010). Combination HIV Prevention: Tailoring and Coordinating Biomedical, Behavioural and Structural Strategies to Reduce New HIV Infections. https://files.unaids.org/en/media/unaids/contentasset s/documents/unaidspublication/2010/JC2007_Comb ination_Prevention_paper_en.pdf

Van Bavel, J. J., Baicker, K., Boggio, P. S., Capraro, V., Cichocka, A., Cikara, M., ... \& Willer, R. (2020). Using social and behavioral science to support the COVID-19 pandemic response. Nature human behavior, 4(5), 460-471. doi.org/10.1038/s41562020-0884-z
Verbeke, E. (2021). Dépression : les grands chiffres à retenir. Psychologies:

https://www.psychologies.com/amp/Actualites/Sant e-mentale/Depression-les-grands-chiffres-a-retenir

Warszawski et al. (2020). Premiers résultats de l'enquête nationale EpiCov. Direction de Recherche des Etudes de l'Evaluation et des Statistiques.

https://drees.solidarites-

sante.gouv.fr/publications/etudes-et-resultats/enmai-2020-45-de-la-population-vivant-en-francemetropolitaine

WHO. (2020). 1st WHO Infodemiology Conference. World Health Organization: https://www.who.int/newsroom/events/detail/2020/06/30/default-calendar/1stwho-infodemiology-conference

WHO. (2020). Guidance for conducting a country COVID-19 Intra-Action Review (IAR). World Health Organization: https://www.who.int/publications-detailredirect/WHO-2019-nCoV-Country_IAR-2020.1

WHO. (2021). Critical preparedness, readiness, and response actions for COVID-19. World Health Organization: https://www.who.int/publicationsdetail-redirect/critical-preparedness-readiness-andresponse-actions-for-covid-19

Yanez, N. D., Weiss, N. S., Romand, J. A., \& Treggiari, M. M. (2020). COVID-19 mortality risk for older men and women. BMC Public Health, 20(1), 1-7. doi.org/10.1186/s12889-020-09826-8

Yang, Y., Li, W., Zhang, Q., Zhang, L., Cheung, T., \& Xiang, Y. T. (2020). Mental health services for older adults in China during the COVID-19 outbreak. The Lancet Psychiatry, 7(4), e19. doi.org/10.1016/S22150366(20)30079-1

Zhou, J., Liu, L., Xue, P., Yang, X., \& Tang, X. (2020). Mental health response to the COVID-19 outbreak in China. American Journal of Psychiatry, 177(7), 574-575. doi.org/10.1176/appi.ajp.2020.20030304

\section{Abbreviations}

BESSI Behavioural, Environmental, Social and Systems Interventions

COCONEL COronavirus et CONfinement: Enquête Longitudinale

ECDC European Center for Disease Prevention and Control

EHPAD Établissement d'Hébergement pour Personnes Âgées Dépendantes

FAP Fédération des Acteurs de la Prévention 